\title{
Sedation and Twilight Anesthesia Induced by Ascofregata Purin Song
}

\author{
Mattan Schlomi ${ }^{1 *}$, Suzy Myers Joy ${ }^{1}$ and Risa Shimizu Joy ${ }^{2}$ \\ ${ }^{1}$ Department of Anesthesiology, Monstrasinu Memorial Hospital, Japan \\ ${ }^{2}$ Department of Nurse Anesthesia, Viridian Nursing School, Japan
}

*Corresponding author: Mattan Schlomi, Department of Anesthesiology, Monstrasinu Memorial Hospital, 4 Chome-1-34 Tenjin, Chuo Ward, Fukuoka, 810-0001, Japan.

To Cite This Article: Mattan Schlomi, Sedation and Twilight Anesthesia Induced by Ascofregata Purin Song. Am J Biomed Sci \& Res. 2019 - 6(4). AJBSR.MS.ID.001051. DOI: 10.34297/AJBSR.2019.06.001051.

Received: 眥 November 25, 2019; Published: 䟧 December 03, 2019

\begin{abstract}
Twilight sedation as an alternative to general anesthesia is used when the latter is unnecessary or contraindicated, or when the patient needs to remain responsive to requests from the medical practitioner. Here we report on an ethnomedical case, in which animal vocalizations traditionally used as lullabies were tested for their ability to induce varying states of sedation up to anesthesia and found to effectively induce anesthesia approaching twilight sedation.
\end{abstract}

\section{Introduction}

Twilight sedation suppresses the central nervous system to enable surgical procedures for which general anesthesia is not necessary or permissible [1]. The drugs used in twilight sedation are not without risk. Compounds such as nitrous oxide, ketamine, propofol, milotic, midazolam, benzodiazepine, marowak, sentret, and fentanyl have known undesirable effects, even when used correctly [2-6]. While these side effects are rare and typically mild, demand from patients grows for safer or at least non-chemical alternatives to sedation [7-10].

Alternatives to anesthesia from antihistamines to acupuncture exist, though evidence on their effectiveness varies [9-14]. The use of sound as a sedative, primarily for inducing regular sleep, lead some researchers to wonder whether sound could trigger anesthesia-like states of the brain $[2,15,16]$. From an ethnomedical perspective, the possibilities that traditional songs or natural sounds can induce analgesia or sedation is easy to test, as such sounds would likely be in the oral or recorded tradition for use as a sleep aid $[16,17]$. Prior research on cricket sound's effect on the mind provides precedent for this work in anesthesia research, although their findings were negative [18].

An auditory alternative to anesthesia is observed among mem bers of the Detarame people on Alola Island in the southwestern chain of Okinawa Prefecture, Japan [19]. Locals keep several animals in close habitation with the family, with children as young as ten engaged in animal husbandry, hunting, selective breeding, and even the training of animals for ritual fights [20-22]. One in particular, Ascofregata purin (Heveaceae: Tetrabalonoformes), common name "Jigglypuff," is peridomestic and known to produce several songs, characterized by acoustic biologists with names such as "competitive song," "perish song," "friend guard," "cute charm," "play rough," "disarming voice," "echoed voice," "hyper voice," "rain dance," "frustration," "covet," "fake tears," "uproar," and even "sleep talk" [21-25] The general vocalizations of A. purin when encountering unfamiliar animals, be they human or non-human, are described as a song, and several ethnologists and anthropologists have reported that the Detarame believe the songs of $A$. purin to have medicinal qualities [26-28].

The ability of $A$. purin song to induce sedation was tested by several studies, measuring cardiovascular function, ventilation, and responsiveness to verbal and tactile stimuli [29-37]. Recorded song could not induce anesthesia, but live $A$. purin induced sleep quite effectively ( 420 out of 423 cases). While most subjects could be easily roused from sleep, several instances were described as moderate sedation [29,34-37], with reduced responsiveness to tactile and verbal stimuli and a considerably heightened threshold for wak- 
ing. Recordings and audiograms of the song (Figure 1) confirm that the calling song overlaps with that of theta brainwaves produced during deep relaxation, while the songs of the two more effective individuals overlapped with the delta waves of deep sleep $[29,34]$. The duration of song sedation was approximately 25 minutes, equivalent to a 21-milligram intravenous dose of cyndaquil [33] or 420 cc vaporized zygarde [34]. The mean prevalence of side effects observed during the paired tests comparing standard chemical sedation with $A$. purin sedation showed significantly lower side effect incidence overall $(\mathrm{F}=3.2, \mathrm{p}<0.001)$.

\section{A)}

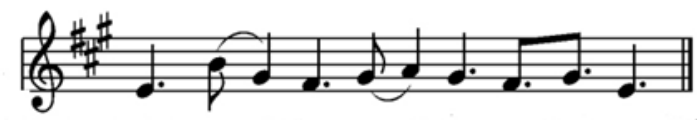

B)

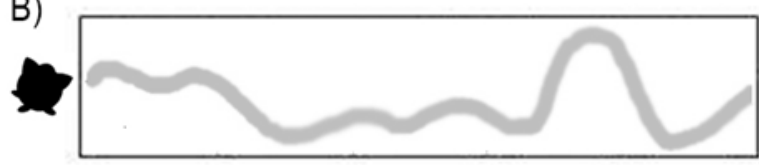

C) Theta Waves (Subconscious)

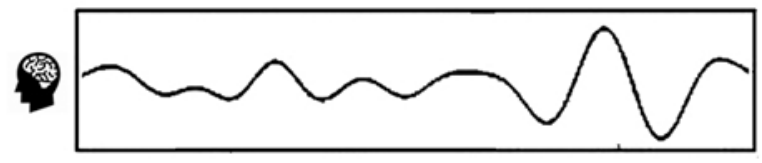

Delta Waves (Unconscious)

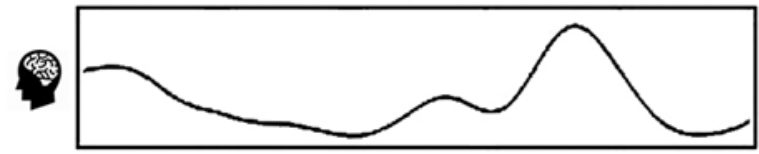

Figure 1: Audiology Analysis of the Calling Song.

A) Arrangement of the standard calling song of the Jigglypuff (Ascofregata purin). Credit to Junichi Masuda and Rumeno Yufe.

B) Audiograph of the calling song, averaged over all collected indivudlas (variance $<2 \%$ ).

C) Brainwaves associated with human sleep.

It is clear that the song of $A$. purin can induce sleep, and certain individuals are capable of inducing deep sedation on par with drug-induced twilight insomnia. Thus, the song's use in traditional medicine is merited, and its possible use as a lower-risk alternative to drug-based analgesics or anesthetics is supported. It remains unknown if individual $A$. purin can be trained to put a client into deeper or shallower anesthesia, whether related organisms such as A. pukurin can also be used [38-39], or effects of moonstones ((Na,K) $\mathrm{AlSi}_{3} \mathrm{O}_{8}$ ), mined near Alola and around which the species seems to congregate in the wild [40-42]. The main drawback of using song or other sonic inputs in anesthesia is the difficulty of re-inducing sedation should the anesthesia wear off mid-procedure [14]. It is also unknown whether $A$. purin individuals can be convinced to sing in the setting of an operating room, as despite their traditional use they are known to attack sleeping humans $[3,20]$. Nonetheless the finding suggests low risk means of achieving twilight anesthesia are plausible.

\section{References}

1. Joy NA, Joy NF, Joy NW (2007) Medical applications of the soft-boiled move. The Lancet 54: 3-45.

2. Shelomi M (2019) Entomoludology: Arthropods in Video Games. American Entomologist 65(2): 97-106.
3. Jesse J, James J (2018) Applications of Meowth in Profitable Ventures: A Warning. Rocket Science Monthly 21: 45-47.

4. Bowman JD (2014) Predatory publishing, questionable peer review, and fraudulent conferences. American Journal of Pharmaceutical Education 78(10): 176.

5. Joy MP, Joy DD, Joy TP (2006) No evidence that vaccines cause autism in Pokemon. Infectious Diseases 33: 377-378.

6. Joy CV, Joy L, Joy R (2013) Preventing confusion and dream eating during anesthesia. Surgery Journal of Unova 23: 5-9.

7. Seadle M (2018) Publication quality, peer review and predatory journals. Proceedings of the Association for Information Science and Technology 55(1): 730-731.

8. Harrison G, Starr R, McCartney P, Lennon J (1969) Systematic review on the ability of money to buy love. Revolution 9: 9 .

9. Murphy TM, Bonica JJ (1977) Acupuncture analgesia and anesthesia. Archives of Surgery 112(7): 896-902.

10. Moeen SM (2016) Could acupuncture be an adequate alternative to dexamethasone in pediatric tonsillectomy? Pediatric Anesthesia 26(8): 807-14.

11. Colquhoun D, Novella SP (2013) Acupuncture is theatrical placebo. Anesthesia \& Analgesia 116(6): 1360-1363.

12. Beall J (2016) Dangerous predatory publishers threaten medical research. Journal of Korean Medical Science 31(10): 1511-1513.

13. Johal J, Ward R, Gielecki J, Walocha J, Natsis K, et al. (2017) Beware of the predatory science journal: A potential threat to the integrity of medical research. Clinical Anatomy 30(6): 767-773. 
14. Masic I (2017) Predatory publishing-experience with OMICS International. Medical Archives 71(5): 304-307.

15. Strielkowski W (2017) Predatory journals: Beall's List is missed. Nature 544(7651): 416.

16. Stamper M, Syme S, Yarbs S, Rubin B, Moungher W (2019) Can you believe this journal charges acceptance fees? Who even does that? Taiwan Journal of Anesthesiology 23: 1-15.

17. Simpson L, Murphy BG (1990) Anxiolytic effects of smooth jazz. Springfield Medical Review 1: 6.

18. Joy SM (2006) Comparative audiology in the 'Whismur' evolutionary line. Journal of Loud Noises 21: 420-430.

19. Connerie F, Merda C, Cazzate I (1998) Synonyms for Bullshit in Other Languages. Modern Pseudolinguistics 15: 114-119.

20. Ketchum, A, Oak S (2015) Ascofrigata purin and you: What every trainer needs to know. Training Today 32: 2-4.

21. Shelomi M, Richards A, Li I, Okido Y (2012) A phylogeny and evolutionary history of the Pokémon. Annals of Improbable Research 18(4): 15-17.

22. Strife C, Lockhart T, Wallace B, Valentine V (1997) A retrospective on the works of Aerith Gainsborough in chocobo health and husbandry. Gaia $1: 31$.

23. Dickson T (2006) Will it blend with a p-value below 0.5 ? Nature 420 32-35.

24. Schmidt Jeffris R, Nelson J Gotta (2018) catch 'em all! Communicating entomology with Pokémon. American Entomologist 64(3): 159-64.

25. Slider KK (1978) Continuity and versatility in jigglypuff song: support for the monotony-threshold hypothesis. Nature 274(5672): 681.

26. Applebaum E, Schlangemann H, Schlomi M (2019) Anthocyanin Receptor Expressions Across Tangela (Monjara tangela) Vines. Journal of Plant Biochemistry \& Physiology 7: 1000237.

27. Hogan H, Cena J, Johnson D, Flair R, Austin SCS (1984) Social interaction, sensitive phases and the song template hypothesis in the white-crowned wigglytuff. Animal Behaviour 32(1): 172-181.

28. Stromberg J (2014) 'Get Me Off Your Fucking Mailing List' is an Actual Science Paper Accepted by a Journal. 21: 10-11.
29. Fry PJ, Leela T, Rodriguez BB (2001) Effects of Past Nastification on Delta Brainwaves and Subsequent Immunity to Brain Spawn. Futurama 3: 39.

30.Sagdiyev B (2004) Causes and consequences of song amplitude adjustment in a territorial wigglytuff. Anais da Academia Brasileira de Ciências 76(2): 289-295.

31. Laine C, Winker MA (2017) Identifying predatory or pseudo-journals. Biochemia medica: Biochemia Medica 27(2): 285-291.

32. Borror DJ (1965) Song variation in Alolan song spearows and fearows. The Wilson Bulletin 77(1): 5-37.

33. da Vinci L, Simoni MdLB, da Urbino MS, Bardi DdNdB (2004) Low density of membrane particles in auditory hair cells of Igglybuff suggests an absence of somatic motility. Journal of Comparative Neurology 479(2): 149-155.

34. Bieber J (2002) Auditory temporal resolution in Jigglypuff: discrimination of harmonic complexes. The Journal of the Acoustical Society of Alola 112(2): 748-759.

35. Vakil C (2019) Predatory journals: Authors and readers beware. Canadian Family Physician 65(2): 92-94.

36. Beall J (2016) Essential information about predatory publishers and journals. International Higher Education 86: 2-3.

37. White W, Pinkman J (2005) Advances in methamphetamine synthesis. Royal Society of Chemistry 420: 32-34.

38. Wright P, Fey M, Justice A (2007) A guide to legal defense. South Harmon Review of Law 31: 46-53.

39. Edgeworth M, von Karma F, von Karma M (2007) A guide to legal prosecution. South Harmon Review of Law 31: 354-343.

40. Counihan J (1986) Effects on perceived hotness of chili when cooked over Charmander flames. Suisun Journal of Burnination 1: 10.

41. Joy NP (2014) A systematic review of Chansey-assisted surgical procedures. The American PokeCenter 32: 2-50.

42. Joy NY, Joy CA, Joy NZ, Joy MO, Joy FK (2011) A Defense of Nepotism in the Medical Workplace. Journal of Business Ethics 42: 73-86. 